\title{
Insights into Human Lck SH3 Domain Binding Specificity: Different Binding Modes of Artificial and Native Ligands ${ }^{\dagger}$
}

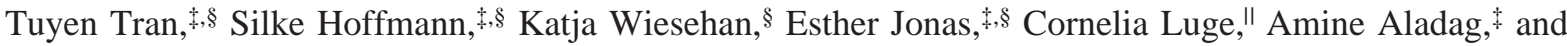 \\ Dieter Willbold*,\$, \\ Institut für Physikalische Biologie, Heinrich-Heine-Universität, 40225 Düsseldorf, Germany, Forschungszentrum Jülich, \\ IBI-2/NMR, 52425 Jülich, Germany, and Institut für Molekulare Biotechnologie, 07745 Jena, Germany
}

Received July 19, 2005; Revised Manuscript Received August 29, 2005

\begin{abstract}
We analyzed the ligand binding specificity of the lymphocyte specific kinase (Lck) SH3 domain. We identified artificial Lck SH3 ligands using phage display. In addition, we analyzed Lck SH3 binding sites within known natural Lck SH3 binding proteins using an Lck specific binding assay on membraneimmobilized synthetic peptides. On one hand, from the phage-selected peptides, representing mostly special class I' ligands, a well-defined consensus sequence was obtained. Interestingly, a histidine outside the central polyproline motif contributes significantly to Lck SH3 binding affinity and specificity. On the other hand, we confirmed previously mapped Lck SH3 binding sites in ADAM15, HS1, SLP76, and NS5A, and identified putative Lck SH3 binding sites of Sam68, FasL, c-Cbl, and Cbl-b. Without exception, the comparatively diverse Lck SH3 binding sites of all analyzed natural Lck SH3 binding proteins emerged as class II proteins. Possible explanations for the observed variations between artificial and native ligandswhich are not due to significant $K_{\mathrm{D}}$ value differences as shown by calculating Lck SH3 affinities of artificial peptide PD1-Y(-3)R as well as for peptides comprising putative Lck SH3 binding sites of NS5A, Sos, and Sam68-are discussed. Our data suggest that phage display, a popular tool for determining SH3 binding specificity, must-at least in the case of Lck-not irrevocably mirror physiologically relevant protein-ligand interactions.
\end{abstract}

Protein tyrosine kinases (PTKs) ${ }^{1}$ are involved in signal transduction pathways that regulate cell growth, differentiation, activation, and transformation. Lck is a lymphoid specific PTK, which is essential for T-cell development and function $(1-3)$. Lck resides predominantly in the cytosol where it interacts with the inner side of the plasma membrane via its hydrophobic myristoylated $\mathrm{NH}_{2}$ terminus (4). It is constitutively associated with the cytoplasmic portions of cell surface receptors CD4 and CD8 $(5,6)$ and plays a key role

\footnotetext{
† This work was supported by a grant from the Deutsche Forschungsgemeinschaft (DFG) to D.W. (Wi 1472/4-2).

* To whom correspondence should be addressed: Forschungszentrum Jülich, IBI-2/NMR, 52425 Jülich, Germany. Telephone: +49 2461 612100. Fax: +49 2461 2023. E-mail: d.willbold@fz-juelich.de.

† Heinrich-Heine-Universität.

$\S$ Forschungszentrum Juelich.

"Institut für Molekulare Biotechnologie.

${ }^{1}$ Abbreviations: aa, amino acid; ADAM, adamalysin; BME, $\beta$-mercaptoethanol; BSA, bovine serum albumin; ELISA, enzyme-linked immunosorbent assay; FasL, Fas ligand; FCS, fetal calf serum; GST, glutathione $S$-transferase; $\mathrm{hDgl}$, human homologue of the Drosophila discs large tumour suppressor protein; HR, horseradish peroxidase; HS1/ LckBP1, hematopoietic lineage cell specific protein 1/Lck binding protein 1; HTLV, human T-cell leukemia virus; Lck, lymphocyte specific kinase; MAPK, mitogen-activated protein kinase; NMR, nuclear magnetic resonance; PBS, phosphate-buffered saline; PI3K, phosphatidylinositol 3-kinase; PTK, protein-tyrosine kinase; Sam68, Src associated in mitosis of $68 \mathrm{kDa}$; SH2 and SH3, Src homology 2 and 3, respectively; SLP-76, SH2 domain containing leukocyte protein of 76 $\mathrm{kDa}$; Sos, Son of sevenless; TBS, Tris-buffered saline; TCR, T-cell receptor; Tio, two-in-one protein of Herpesvirus ateles strain 73; Tip, tyrosine kinase interacting protein; WASP, Wiskott-Aldrich syndrome protein; TMB, 3,3',5,5'-tetramethylbenizidine.
}

in T-cell antigen receptor (TCR)-linked signal transduction pathways (7). As a member of the Src family of kinases, Lck shows their common architecture consisting of an $\mathrm{N}$-terminal unique domain, followed by the regulatory $\mathrm{SH} 3$ and $\mathrm{SH} 2$ domains and by the tyrosine kinase domain containing the active site. The SH3 domain binds to polyproline motifs and is required for association of the kinase with many intracellular substrate or binding partners.

Various Lck SH3 domain interacting proteins have been reported, e.g., c-Cbl (8, 9), CD28 (10), PI3K (11), HS1/ LckBP1 (12), SLP-76 (13), CD2 (14), Sos (15), ADAM15 (16), NS4A (17), MAP kinase (18), hDlg (19), and Sam-68 (20). So far, only for some of them have exact binding sites for Lck SH3 been experimentally mapped. Therefore, no prediction of a consensus sequence for Lck SH3 binding ligands has been deduced up to now.

The Protein Data Bank (PDB) includes the structures of almost 30 different SH3 domains, many of them determined repeatedly from the same organism or from different organisms. Additionally, the structures of more then $20 \mathrm{SH} 3$ domains with physiologically relevant or engineered ligands have been deposited. As known from these complex structures, binding of polyproline SH3 ligands occurs at a shallow hydrophobic patch formed by residues of the SH3 RT loop, the $\mathrm{n}$-src loop, and the turn connecting strands $\beta_{4}$ and $\beta_{5}$ (21). SH3 ligands are pseudosymmetrical and may therefore bind in one of two opposite orientations $(22,23)$. Ligands that bind in one orientation or the other are divided into different classes. Class I ligands conform to the consensus 
$+\mathrm{p} \Psi \mathrm{Pp} \Psi \mathrm{P}$ and class II ligands to $\Psi \mathrm{Pp} \Psi \mathrm{Pp}+$, where the uppercase positions represent conserved residues that contact the SH3 domain and confer specificity and the lowercase residues represent scaffolding residues that tend to be proline. $\Psi$ and + represent sequence positions occupied by aliphatic and basic residues, respectively. Particularly the position of the basic residue, mostly an arginine, relative to the core proline residues determines ligand orientation (24). More recently, several exceptions have been described (25), suggesting that the binding potential of SH3 domains might be larger than anticipated so far.

Specificities of a great number of $\mathrm{SH} 3$ domains have been determined by screening of a phage-displayed peptide library or immobilized synthetic peptide arrays. Thus, ligand preferences of the SH3 domains of Src (25-29), Yes, Fyn, Lyn (30, 31), PI3K (31), Grb2-N, Grb2-C, p53bp2, Cortactin, Crk, $\mathrm{Abl}, \mathrm{PlC} \gamma$ (30), Itk (32), Cap (33), Eps8 (34), amphysin, endophilin (35), and Abp1 (36), have been published. Recently, several comprehensive surveys have covered the functional and structural aspects of SH3-mediated interactions (37-40), and extensive systematic approaches have been undertaken to make the peptide recognition specificity mediated by SH3 domains predictable $(41,42)$. The previously available data do not support the idea of a simple recognition code (25). Nevertheless, some recognition rules began to emerge, and $\mathrm{SH} 3$ domains from the entire yeast repertoire could tentatively be assigned to eight different specificity classes (25). Statistical methods based on position specific profiles (42) or neural networks (41) still cannot provide highly confident results due to the lack of "balanced" input data.

In the case of Lck SH3, no screenings of phage-displayed randomized peptide libraries or combinatorial synthetic peptide arrays were reported so far. We therefore analyzed the ligand binding specificity of the Lck SH3 domain by searching for artificial peptide ligands screening a phage display peptide library. Additionally, we analyzed a variety of Lck SH3 binding sites in nearly every known and sufficiently characterized cellular Lck SH3 binding partner using membrane-immobilized synthetic peptides. A comparison of the two data sets should afford deeper insights into Lck SH3 binding specificity, as possibly can be obtained by the common phage display approach alone.

\section{MATERIALS AND METHODS}

Preparation of Glutathione S-Transferase (GST)-SH3 Fusion Proteins. The expression system for the GST-Lck SH3 fusion protein was described previously $(43,44)$. DNA constructs encoding GST fusions to the Fyn (aa 80-146), Hck (aa 61-141), PI3K (aa 1-83), Src (aa 79-150), and Abl (aa 59-126) SH3 domains were generated by PCR cloning of the appropriate DNA fragments using IMAGE cDNA clones IMAGp998C136535, IMAGp958H201705, IMAGp998J21580, IMAGp998N195197, and DKFZp762G2$44 \mathrm{Q}$, respectively. PCR fragments were digested with Bam HI and $\mathrm{XhoI}$ and inserted into pGEX-6P-2 (Amersham Biosciences, Freiburg, Germany). Integrities of the constructs were confirmed by DNA sequencing. GST $-\mathrm{SH} 3$ fusions and free SH3 domains were prepared essentially as described previously for the GST-Lck SH3 fusion protein $(43,44)$. Only thrombin cleavage was replaced by a PreScission protease (Amersham Biosciences) cleavage. The identities of the SH3 domains were confirmed by mass spectroscopy. Purity of the proteins was checked by SDS-PAGE. Concentrations of all protein solutions were determined according to their absorbance at $280 \mathrm{~nm}$ (45).

Biopanning. A commercially available peptide library kit (PhD.-12 Peptide Library Kit, New England Biolabs, Inc., Beverly, MA) containing $2.7 \times 10^{9}$ independent clones was used to perform the biopanning by following the manufacturer's instructions (Instruction manual, version 2.7) with minor modifications: the commonly used TBS buffer [50 $\mathrm{mM}$ Tris- $\mathrm{HCl}(\mathrm{pH} 7.7)$ and $150 \mathrm{mM} \mathrm{NaCl}]$ and the $0.1 \mathrm{M}$ $\mathrm{NaHCO}_{3}$ solution for target immobilization were replaced with a Tris-Bis buffer [20 mM Bis-Tris ( $\mathrm{pH} 6.5), 150 \mathrm{mM}$ $\mathrm{NaCl}$, and $1 \mathrm{mM} \mathrm{BME]}$. Recombinant GST-Lck SH3 fusion protein was used as bait. Progress of affinity selection was tracked using the anti-phage ELISA detection system described in detail below.

Determination of Lck SH3 Binding Activity of Enriched Sublibraries or Single Affinity-Purified Phage Clones (antiphage ELISA). Proteins at a concentration of $10 \mu \mathrm{g} / \mathrm{mL}$ in Tris-Bis were immobilized on microtiter plates overnight at $4{ }^{\circ} \mathrm{C}$. Remaining binding sites were blocked with blocking buffer (Bis-Tris supplemented with $10 \mathrm{mg} / \mathrm{mL}$ BSA) for 2 h. Here, $100 \mu \mathrm{L}$ of phage suspension (amplified phages before or after each selection round or suspensions from single phage clones) preincubated with $100 \mu \mathrm{L}$ of blocking buffer for $20 \mathrm{~min}$ was added and the mixture incubated for $1 \mathrm{~h}$. After the mixture had been washed with Tris-Bis, HRPconjugated anti-M13 antibody (Amersham Biosciences, Uppsala, Sweden) diluted 1:5000 was added and incubated for $1 \mathrm{~h}$. Plates were washed with Tris-Bis, and bound phages were detected via the HRP-conjugated antibody using TMB and $\mathrm{H}_{2} \mathrm{O}_{2}$ (46). After 10-30 min, the colorimetric reaction was stopped by addition of $100 \mu \mathrm{L}$ of concentrated $\mathrm{H}_{2} \mathrm{SO}_{4}$. Absorption at $450 \mathrm{~nm}$ was recorded with a Fluostar optima microplate reader (BMG Labtechnologies, Offenburg, Germany) at $450 \mathrm{~nm}$.

DNA Sequence Determination. Single-stranded DNA was prepared using a QIAprep 96 M13 kit (Qiagen, Hilden, Germany) according to the manufacturer's instructions. Sequencing was conducted using the Dye Terminator Cycle Sequencing kit (PE Applied Biosystems, Warrington, U.K.), and reaction products were separated by a $4 \%$ denaturating urea PAGE and analyzed with an ABI Prism 377 DNA sequencer equipped with the API Prism sequencing analysis 3.4.1 tool (Applied Biosystems, Langen, Germany). Sequence analyses were performed with the "GCG" Wisconsin Package, version 10.3 (Genetic Computer Group Inv., Madison, WI).

Spot Assay. Peptides bound to continuous cellulose membrane supports were purchased from JPT Peptide Technologies GmbH (Berlin, Germany). All peptides were amino-terminally acetylated. Each spot carried $\sim 5 \mathrm{nmol}$ of peptide covalently bound to the cellulose membrane. For the immunoassay, the membrane was blocked overnight with T-TBS (TBS with $0.05 \%$ Tween 20) complemented with $10 \%$ FCS. After the membrane had been washed with T-TBS, the membrane was incubated with $10 \mathrm{~mL}$ of T-TBS, $10 \%$ FCS, and the appropriate GST-SH3 fusion protein (1 $\mu \mathrm{g} / \mathrm{mL}$ ) for $4 \mathrm{~h}$, followed by an additional washing step with T-TBS. The membrane was incubated with a 1:2000 dilution 
of a HRP-conjugated anti-GST antibody (Novus Biologicals, Inc., Littleton, $\mathrm{CO}$ ) for $2 \mathrm{~h}$ and then washed three times with T-TBS for $30 \mathrm{~min}$. Bound antibody was quantified using chemiluminescence detection (ChemiDoc, Bio-Rad, München, Germany) 1 min after addition of the substrate (Pierce Biotechnology, Inc., Rockford, IL). Spot intensity values were calculated with the Quantity One software tool from Bio-Rad using background subtraction. The membrane was regenerated by washing with $\mathrm{H}_{2} \mathrm{O}$ and sequential treatment with $8 \mathrm{M}$ urea supplemented with $10 \%$ SDS and $100 \mathrm{mM}$ 2-mercaptoethanol overnight and then twice for $1 \mathrm{~h}$, three times for $1 \mathrm{~h}$ with $10 \%$ acetic acid in $50 \%$ ethanol, twice for 30 min with T-TBS, three times for $1 \mathrm{~h}$ at $50{ }^{\circ} \mathrm{C}$ with $62.5 \mathrm{mM}$ Tris- $\mathrm{HCl}$ (pH 6.7) and $100 \mathrm{mM}$ 2-mercaptoethanol, three times for 30 min with $10 \times$ PBS, and three times for 30 min with T-TBS.

Fluorescence Spectroscopy and Calculation of the Binding Constants. Measurements of binding affinities based on the interaction of the peptides with aromatic residues (predominantly tryptophan) in the SH3 domains were performed essentially as previously described (43) using a Perkin-Elmer LS 55 fluorescence spectrometer at excitation and emission wavelengths of 290 and $345 \mathrm{~nm}$ (slit width, $3.4 \mathrm{~nm}$ ), respectively. A mini magnetic stirrer was used to mix the solution in a $3 \mathrm{~mL}$ quartz fluorescence cell. The sample temperature was held constant at $21.5^{\circ} \mathrm{C}$ using a circulating water bath. Peptides were purchased as reversed phase highperformance liquid chromatography-purified products (JPT Peptide Technolgies GmbH, Berlin, Germany) and were Nand C-terminally acetylated and amidated, respectively. Identities were confirmed by matrix-assisted laser desorption ionization time-of-flight mass spectrometry (MALDI-TOFMS). To obtain the titration curves for calculating the binding constants, peptides from stock solutions in $\mathrm{H}_{2} \mathrm{O}$ were added in small increments to $1.6 \mathrm{~mL}$ of PBS and $1 \mathrm{mM}$ DTT containing the free $\mathrm{SH} 3$ domain at $0.5 \mu \mathrm{M}$. Upon addition of the peptide solution, changes in fluorescence were measured. The change of the protein concentration that occurred as a result of peptide addition was properly corrected with fluorescence values from a control titration with the peptide being replaced with buffer. Because the PD1 peptide contains a tyrosine residue, the control titrations contained buffer with tyrosine amide equal to the PD1 peptide concentration of the respective titration step.

The experimental data were fitted according to eq 1

$$
\begin{aligned}
& F=F_{\text {min }}+\left[\frac{\left[\mathrm{P}_{\text {tot }}\right]+\left[\mathrm{L}_{\text {tot }}\right]+K_{\mathrm{D}}}{2}-\right. \\
& \sqrt{\left.\frac{\left(\left[\mathrm{P}_{\text {tot }}\right]+\left[\mathrm{L}_{\text {tot }}\right]+K_{\mathrm{D}}\right)^{2}}{4}-\left[\mathrm{P}_{\text {tot }}\right]\left[\mathrm{L}_{\text {tot }}\right]\right] \frac{\left(F_{\text {max }}-F_{\text {min }}\right)}{\left[\mathrm{P}_{\text {tot }}\right]}}
\end{aligned}
$$

where $\left[\mathrm{L}_{\mathrm{tot}}\right]$ is the total peptide (ligand) and $\left[\mathrm{P}_{\text {tot }}\right]$ is the total SH3 (protein) concentration at each measurement point, $F$ is the measured fluorescence intensity at the particular peptide concentration, $F_{\max }$ is the observed maximal fluorescence intensity of the protein when saturated with the peptide, and $F_{\min }$ is the fluorescence intensity of the protein at the titration start. We obtained eq 1 by solving the standard $1: 1$ stoichiometric binding equation $K_{\mathrm{D}}=\left[\mathrm{P}_{\text {free }}\right]\left[\mathrm{L}_{\text {free }}\right] /$ [complex $]$, where $\left[\mathrm{P}_{\text {free }}\right]=\left[\mathrm{P}_{\text {tot }}\right]-[$ complex $]$ and $\left[\mathrm{L}_{\text {free }}\right]=$
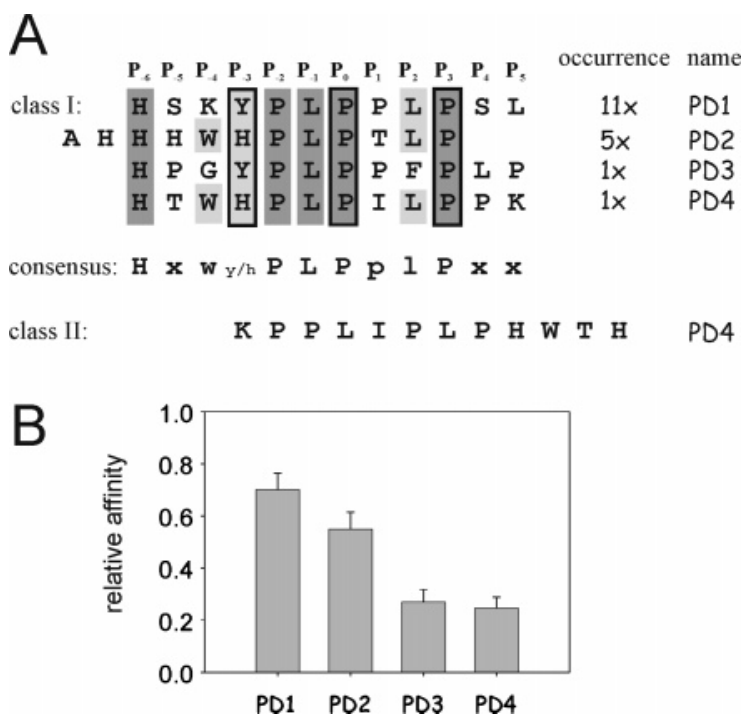

FIGURE 1: Phage display-selected peptides and their relative binding affinities for Lck SH3. (A) Lck SH3 binding peptides selected by phage display. Recombinant GST-Lck SH3 fusion protein was used for biopanning of the phage display peptide library. The amino acid sequences of peptides displayed by positive phage clones were deduced from the DNA sequences of the corresponding gene III fusions. Peptide sequences are given in the one-letter amino acid code. Dark gray and gray bars indicate highly and moderately conserved amino acids, respectively. To the right of the peptide name, a number denotes how often the respective sequence was found among the independent isolates. Below the class I sequence list, the resulting consensus sequence is indicated. Uppercase letters represent residues conserved in all sequences, and lowercase letters represent residues that are found in at least $50 \%$ of the peptide sequences. The proline residues belonging to the strictly conserved PxxP motif of SH3 ligands and the amino acid which covers the "compass position" $\mathrm{P}_{-3}$ are boxed. The designations of the positions in the peptides sequences are according to ref 72 . Sequence PD4 is additionally shown as class II ligand in the $\mathrm{C}$ - to $\mathrm{N}$-terminal direction from left to right, because binding of this peptide is theoretically possible in both orientations. (B) Relative binding affinities of the selected peptide sequences were estimated by an anti-phage ELISA. Approximately $10^{9}$ phage particles, displaying the peptide indicated below each bar, were adsorbed to GST-Lck SH3 protein-coated vials of a microtiter plate. Retained phages were revealed by a HRP-conjugated anti-M13 antibody and TMB and $\mathrm{H}_{2} \mathrm{O}_{2}$ as the substrate. For each phage clone, the mean value and the standard deviation of 10 colorimetric reactions are shown.

$\left[\mathrm{L}_{\text {tot }}\right]-$ [complex] and subsequent replacement of [complex] $=\left[\mathrm{P}_{\mathrm{tot}}\right]\left(F-F_{\min }\right) /\left(F_{\max }-F_{\min }\right)$ without applying simplifications. Nonlinear regression curve fitting was carried out to fit the experimental data to the equation, with $F_{\max }$ and $K_{\mathrm{D}}$ as fitted parameters.

\section{RESULTS}

In Vitro-Selected Lck SH3 Ligands Follow a Class I Consensus Hxw(y/h)PLPplP. To determine the binding specificity of the human Lck SH3 domain, we used recombinant GST-Lck SH3 fusion protein to screen a phagedisplayed random dodecapeptide library. After three selection cycles, 20 single clones were randomly chosen for further analysis. All of them were assayed for Lck SH3 binding activity employing anti-phage ELISAs to eliminate false positive clones. Altogether, 18 of the originally chosen phages exhibited positive results. The amino acid sequences of the peptides presented on these phages, as deduced from DNA sequence analysis, are shown in Figure 1A. More than $60 \%$ of the obtained phages carried the same dominating 
peptide, named "PD1". All sequences obtained from the screening procedure can be represented by the consensus sequence $N$-Hxw (y/h)PLPplP (Figure 1A), where uppercase letters represent residues conserved in all sequences and lowercase letters show residues that are found in at least 50\% of the peptide sequences.

The core of the consensus sequence (LPplP) obtained from the phage display screening (Figure 1A) nicely fits to the common features of $\mathrm{SH} 3$ binding peptides. In detail, two "LP" dipeptides were conserved in three of the four selected peptides (PD1, PD2, and PD4) representing 17 of 18 sequences in total. The "bridging" proline residue, frequently called a "scaffolding" residue (23), is present in PD1 and PD3 peptides (Figure 1A). Additional residues of the ligand that are $\mathrm{N}$-terminal (class I) or C-terminal (class II) relative to the proline-rich motif are able to form additional contacts to the SH3 surface (23). Such "extra binding regions" were reported and play a role in the affinity and specificity of SH3-ligand complexes (47). On the basis of the positioning of their "aliphatic-proline" dipeptides within the 12-mer peptides, we assume a type I orientation for PD1-PD3, although surprisingly none of them reveals the very common positively charged amino acid at position $\mathrm{P}_{-3}(24,39)$, which usually contacts a conserved aspartate residue located at the end of the RT loop via a salt bridge. In a control screen, which was conducted under the same conditions as the experiment described here, but using a different library lot, again no arginine was selected at position $\mathrm{P}_{-3}$ (data not shown). Likewise for PD4, the positioning of the aliphaticproline dipeptides argues for a type I orientation, but here a lysine residue at the anchor position typically for a class II ligand would also be consistent with binding in a type II orientation. Thus, PD4 theoretically seems to be able to bind $\mathrm{SH} 3$ domains in either one orientation or in both (Figure 1A).

To semiquantitatively determine the relative binding affinities of the selected peptides for the Lck SH3 domain, an anti-phage ELISA was carried out (Figure 1B). Peptide PD1 exhibited the highest affinity for Lck SH3, followed by peptide PD2 and peptides PD3 and PD4. This is in accordance with the observed predominant occurrence of PD1 (11 of 18 sequences) and PD2 (5 of 18 sequences) after three selection rounds.

Potential Key Residues of the Selected Peptides for Lck SH3 Binding outside the Proline-Rich Core. Two peptide positions outside the proline-rich core motif that are completely $\left(\mathrm{P}_{-6}\right)$ or moderately conserved $\left(\mathrm{P}_{-4}\right)$ among the selected sequences (Figure 1A) were further assayed for their role in Lck SH3 binding. The invariant His residue at $\mathrm{P}_{-6}$ and the Trp residues in PD2 and PD4 at $\mathrm{P}_{-4}$ were exchanged with alanine residues at the respective peptide positions and probed for binding to Lck and other $\mathrm{SH} 3$ domains in the spot assay (Figure 2A). Additional peptides were used to check for unspecific binding to either acidic, basic, aromatic, or polyalanine peptides. Only Fyn SH3 exhibited weak but significant binding to the basic peptide. Spot intensities of the Lck SH3 binding assay are more quantitatively summarized in Figure 2B.

As expected, the replacement of the invariable prolines $\left(\mathrm{P}_{0}\right.$ and $\left.\mathrm{P}_{3}\right)$ within the proline-rich core motifs and residue $\mathrm{P}_{-3}$ with alanines abolished interaction of these control peptides with Lck and any other SH3 domain. The only exception is binding of Fyn SH3 to the PD4 control peptide, possibly due to its unspecific binding to basic peptides. PD3 did not exhibit binding to Lck SH3. This might indicate a somewhat high threshold value for a positive binding signal in the spot assay. Substitutions of the selected His residue at $\mathrm{P}_{-6}$ with alanine $[\mathrm{H}(-6) \mathrm{A}$ variants $]$ completely weakened PD1 and PD2 binding and significantly reduced the level of binding of PD4 to Lck SH3. This is very surprising, especially because binding of Hck, Src, and Fyn to PD1 H(6)A was not abolished (Figure 2A). PD2 and PD4 peptide variants with tryptophan to alanine substitutions at position $\mathrm{P}_{-4}[\mathrm{~W}(-4) \mathrm{A}$ variants] also lost binding to Lck SH3 (Figure 2B).

Comparative Binding Studies of the PD Peptides with Different SH3 Domains. SH3 domain specificities of the Srctype kinases Src, Hck, and Fyn are known to be very similar. Therefore, we investigated the binding properties of the phage display screening-obtained PD peptides and their variants additionally with Src, Hck, and Fyn, but also with $\mathrm{Abl}$ and PI3K SH3 domains (Figure 2A). Not surprisingly, the spot patterns after binding to Lck and Src, and to a somewhat lesser extent, Hck and Fyn SH3 domains, were very similar to each other. The non Src-type Abl and PI3K $\mathrm{SH} 3$ domains, in general, bound the PD peptides and their variants with drastically reduced affinity, reflecting their distinct ligand preference.

The most obvious difference among Lck, Src, Hck, and Fyn SH3 domains is the role of histidine at position $\mathrm{P}_{-6}$. In general, histidine at this position seems to be more important for Lck than for Hck, Src, and Fyn SH3 binding. The differences are small but significant. This will be shown in more detail using a substitution analyses for Lck and Src SH3 domains, as will be described later in the text. Another interesting difference among Lck, Src, Hck, and Fyn SH3 domain binding is recognition of the PD2 peptide. Only Lck and Src SH3 show a detectable interaction with the PD2 peptide, whereas the Hck and Fyn SH3s seem to bind only its $\mathrm{H}(-3) \mathrm{R}$ variant. Further, on the basis of its amino acid sequence, peptide PD4 is principally able to bind in both, type I and type II, orientations. It contains a histidine at the anchor position $\left(\mathrm{P}_{-3}\right)$ if binding is in the type I orientation. Lysine occupies the anchor position if binding is anticipated in the type II orientation. To elucidate the orientation of binding of PD4 to the SH3 domains under investigation, peptide variants $\mathrm{PD} 4 \mathrm{H}(-3) \mathrm{A}$ and $\mathrm{PD} 4 \mathrm{~K}(+5) \mathrm{A}$ were used for spot binding assays. Interaction with the PD4 $\mathrm{H}(-3) \mathrm{A}$ peptide would suggest PD4 to be bound by the respective SH3 domain in the type II orientation. On the other hand, interaction with the PD4 $\mathrm{K}(+5) \mathrm{A}$ peptide argues for the type I orientation of the bound peptide. Our results clearly indicate a type I orientation of PD4 when interacting with Lck and $\mathrm{Src} \mathrm{SH} 3 \mathrm{~s}$, and a type II orientation when interacting with the SH3 domains of Hck or Fyn. It is notable that the reported PD4 orientation difference is not detected with variant PD4 $\mathrm{H}(-3) \mathrm{R}$ having the strong arginine anchor at position $\mathrm{P}_{-3}$. This peptide variant yielded very strong signals for all four Src-type PTK SH3 domains, which would argue for a type I orientation of PD4 $\mathrm{H}(-3) \mathrm{R}$ in each case.

As already mentioned for Lck SH3 (Figure 2B), substitution of tryptophan at position $\mathrm{P}_{-4}$ with alanine abolished binding of PD2 to Src SH3, and of PD4 to Src and Hck $\mathrm{SH} 3$, too. Thus, in the originally selected peptides, the 


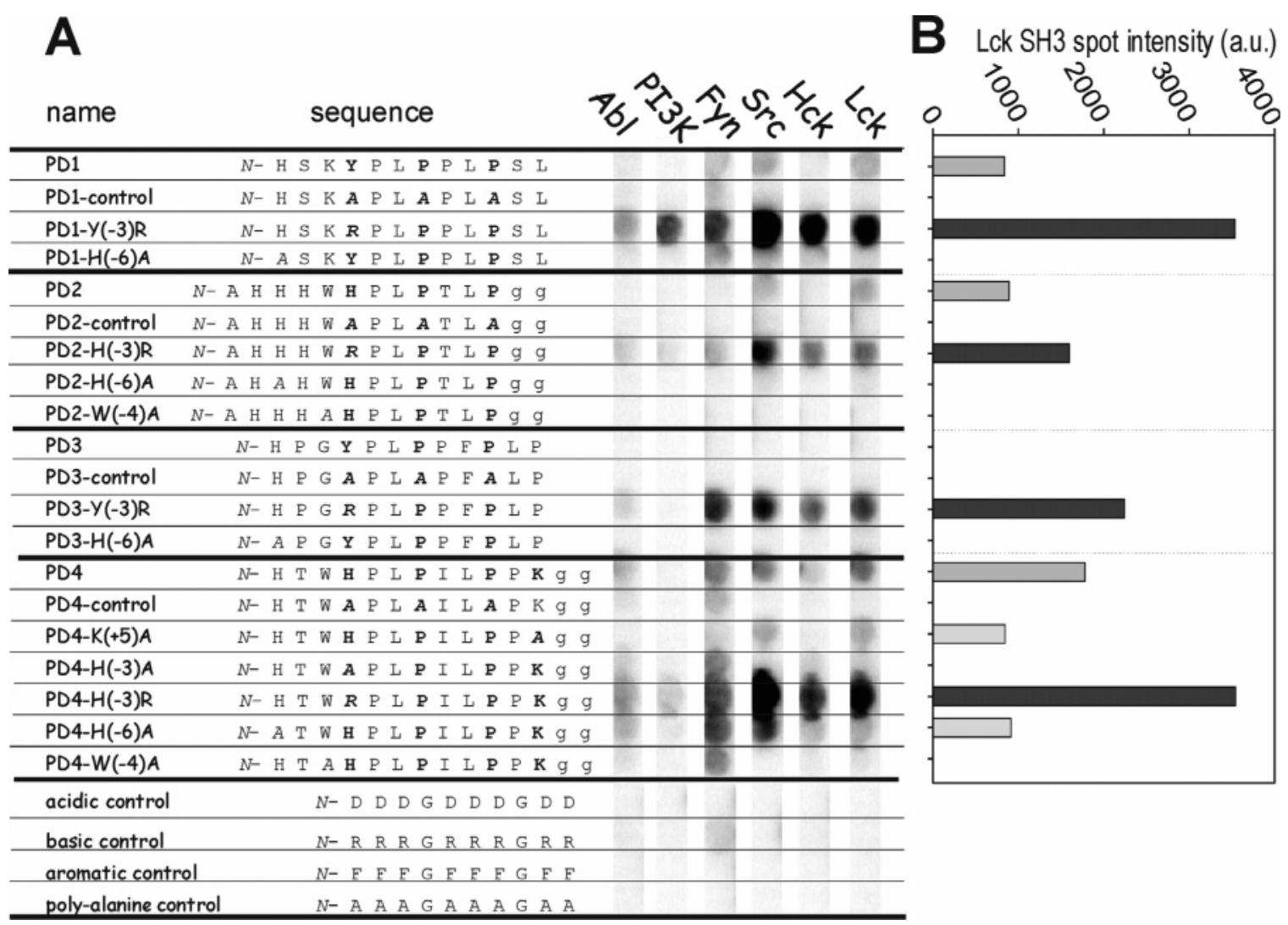

FIGURE 2: Affinities of the phage-selected peptides and variants thereof for Lck and other SH3 domains. (A) Analyses of the binding affinities of the phage-selected peptides and variants for different SH3 domains using the spot membrane technology. After incubation with one of the different GST-SH3 domains, the peptide-bound SH3 fusion proteins were detected by a HRP-conjugated anti-GST antibody and visualized by chemiluminescence. Names and sequences of the immobilized peptides as well as the used GST-SH3 domains are given. Variations of the originally selected peptides are shown in italics and are part of the peptide names with the affected peptide position given in parentheses. The proline residues belonging to the strictly conserved PxxP motif of SH3 ligands and the amino acid which covers $\mathrm{P}_{-3}$ are in bold. To ensure proper spacing of the PxxP motifs from the membrane support, all PD2 and PD4 peptides have been C-terminally elongated by two glycine residues. (B) Quantitative representation of the spot intensities obtained after incubation of the membrane with the GST-Lck SH3 fusion protein. Intensities for each peptide position were determined after background subtraction. The arrangement of the peptides is in the same order as in panel A.

presence of an aromatic amino acid at this position is required for binding. The situation is not clear for Fyn SH3 and PD4 $\mathrm{W}(-4) \mathrm{A}$. Unspecific binding seems to make a substantial contribution to the binding of Fyn SH3 to PD4 and its variants.

The Selected Histidine and Tyrosine Residues at Ligand Position $P_{-3}$ Are Suboptimal for Lck SH3 Binding Affinity. With the exception of Abl, the "compass" pockets of most SH3 domains contain a common acidic residue at the end of the RT loop, which is responsible for the preference of arginine (or sometimes lysine) at ligand position $\mathrm{P}_{-3}$ immediately preceding (binding in the type I orientation) or following (binding in the type II orientation) the core prolinerich sequence of the peptide ligand (24). The presence of a neutral residue at the respective position in the Abl SH3 RT loop is in accordance with its preference for aromatic residues at position $\mathrm{P}_{-3}(31,48)$. The $\mathrm{SH} 3$ domain of Lck, like those of most other Src-type tyrosine kinases, contains an aspartic acid residue at the relevant RT loop position (D79). Thus, it is unexpected that none of the peptides identified in the screening procedure contains an arginine at position $\mathrm{P}_{-3}$. At least one peptide without a basic residue, actually with a tyrosine, at position $\mathrm{P}_{-3}$ was described that binds to the $\mathrm{SH} 3$ domain of Fyn. The 3BP2-derived peptide PPAYPPPPVP, which is a physiological Abl ligand, is able to bind Fyn SH3 (49), although this may not be physiologically relevant (50).
To investigate the role of the histidine or tyrosine residues in PD1-PD4 at position $\mathrm{P}_{-3}$ for Lck SH3 binding, variants thereof carrying arginine instead of tyrosine or histidine at position $\mathrm{P}_{-3}$ were investigated for binding to GST-tagged Lck SH3 in the spot assay. Indeed, affinity for Lck SH3 was increased for all four peptide variants (Figure 2A). Obviously, the presence of an arginine residue at position $\mathrm{P}_{-3}$ enhances ligand affinities of the peptides for Lck SH3 (Figure 2B). In the case of PD3, binding affinity was detectable only for the arginine variant. The arginine variant of PD1 [PD1-Y(3)R] showed a 2-fold increase in affinity compared to that of PD1 as measured by the changes in the intrinsic Lck SH3 tryptophan fluorescence upon binding of the corresponding synthetic peptides PD1 and PD1-Y $(-3) \mathrm{R}$ (Table 1). Thus, the selection procedure yielded peptide sequences which were at least in the case of ligand position $\mathrm{P}_{-3}$ not affinity optimized. This might be explained by the great but limited diversity of the phage-displayed peptide library used for the screening. Additionally, it is known that arginines in the random peptide sequences of phage display libraries interfere with the secretion of the minor coat protein to which they are fused as well as with phage infectivity. Therefore, peptide variants with basic residues are slightly underrepresented in the starting library (51). Also, we cannot exclude the possibility that, under the screening conditions that were used, phage-fused peptides with His or Tyr at position $\mathrm{P}_{-3}$ 
Table 1: Affinity Measurements of Artificial Peptides PD1 and PD1-Y(-3)R and Peptides Derived from Native Lck SH3 Binding Proteins with the Lck SH3 Domain ${ }^{a}$

\begin{tabular}{lclc}
\hline peptide & $K_{\mathrm{D}}(\mu \mathrm{M})$ & peptide & $K_{\mathrm{D}}(\mu \mathrm{M})$ \\
\hline PD1 & $46.2 \pm 0.4$ & Sos-2 & $34.6 \pm 1.8$ \\
& $47.3 \pm 2.5$ & & $42.1 \pm 2.3$ \\
PD1-Y(-3)R & $24.8 \pm 1.4$ & NS5A-6 & $20.5 \pm 0.7$ \\
& $21.8 \pm 0.9$ & & $22.2 \pm 0.6$ \\
Sam68-1 & $115.9 \pm 11.4$ & & \\
& $168.0 \pm 13.4$ & & \\
\hline
\end{tabular}

${ }^{a}$ The values were determined from fluorescence titration experiments. Each measurement was carried out in duplicate, and the standard deviation of each experiment is given. The amino acid sequences of the peptides are HSKYPLPPLPSL (PD1), HSKRPLPPLPSL [PD1-Y(3)R], PSRQPPLPHRSRGG (Sam68-1), VPVPPPVPPRRRPES (Sos2), and TKAPPIPPPRRKRTV (NS5A-6).

are in the case of Lck SH3 binding in fact more positively selected than peptides with Arg at the corresponding position, e.g., because of a more favorable ratio of association and dissociation rates of such phages.

Position $P_{-6}$ of PDI-Y(-3)R Is Preferably Occupied by Histidine and May Be a Specificity Determinant for Lck SH3 Binding. Phage-fused PD1 exhibited the highest relative affinity for Lck SH3 of the phage-selected peptides (Figure $1 \mathrm{~B})$, and its engineered variant PD1-Y $(-3) \mathrm{R}$ exhibited a $K_{\mathrm{D}}$ of $\sim 25 \mu \mathrm{M}$, a 2-fold enhanced affinity for Lck SH3 (Table 1). Therefore, PD1-Y(-3)R seems to be a promising candidate for designing a high-affinity Lck SH3 ligand. We performed a substitution analysis on the basis of PD1-Y(3)R. Four of the five sequence positions $\left(\mathrm{P}_{-2}, \mathrm{P}_{-1}, \mathrm{P}_{0}\right.$, and $\mathrm{P}_{3}$ ) that were invariant among the $\mathrm{PD}$ peptides and the arginine at position $\mathrm{P}_{-3}$ were kept constant. All seven other positions were substituted with all 19 other amino acids (Figure 3A). Whenever histidine at $\mathrm{P}_{-6}$ is exchanged with another amino acid, binding to Lck SH3 is almost completely abolished. Only if the histidine is exchanged with arginine approximately one-third of the binding affinity is retained. This is in perfect agreement with the phage display screening result.

Figure 3B summarizes the spot intensities of the $\mathrm{P}_{-6}$ substitution peptides incubated with Lck and Src SH3 domains. Src $\mathrm{SH} 3$ also favors histidine at position $\mathrm{P}_{-6}$. However, a variety of substitutions (Arg, Lys, Ile, Leu, Pro, and $\mathrm{Phe}$ ) are well tolerated. Thus, histidine at position $\mathrm{P}_{-6}$ seems to be a strong specificity determinant for Lck SH3 peptides that bind in the type I orientation.

Substitution Analysis Reveals Variants with Increased Lck SH3 Binding Affinity Compared to That of PDI-Y(-3)R. Obviously, ligand positions $\mathrm{P}_{-5}, \mathrm{P}_{-4}, \mathrm{P}_{1}, \mathrm{P}_{2}, \mathrm{P}_{4}$, and $\mathrm{P}_{5}$ tolerate a variety of different substitutions (Figure 3 ). This is in accordance with the observed sequence variation among the PD peptides at these positions. Most of the single-aminoacid-substituted peptide derivatives of PD1-Y $(-3) \mathrm{R}$ bind to Lck SH3 with affinities similar to that of PD1-Y(-3)R. Binding affinity seems to be dramatically increased when positions $\mathrm{P}_{-5}$ and $\mathrm{P}_{-4}$ are replaced with $\mathrm{Phe}$ and Arg, respectively. Other substitutions do not seem to contribute that much. In general, the level of binding is reduced drastically when any position tested is replaced with Trp, Tyr, Cys, Asp, or Glu. Peptide HFKRPLPPLPS with a S(5)F substitution shows the strongest signal of all tested
A Lck SH3:

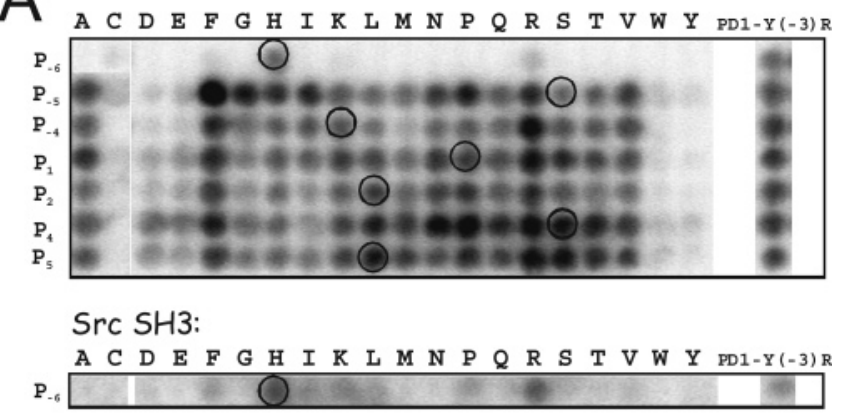

B

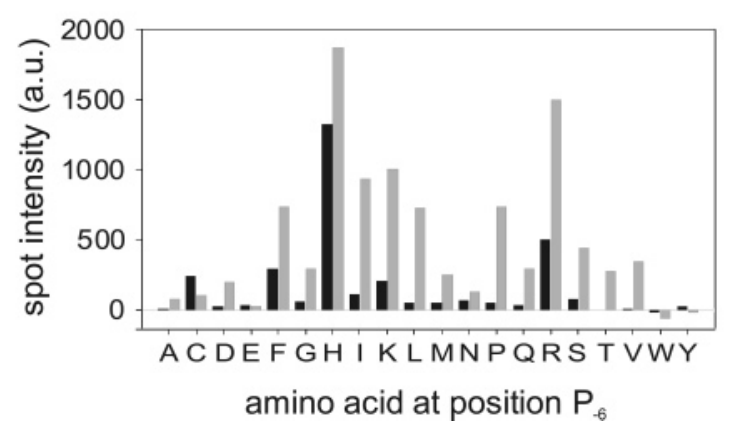

FIGURE 3: Amino acid substitution analysis of PD1-Y(-3)R. (A) Substitution analyses of the engineered phage-selected peptide PD1$\mathrm{Y}(-3) \mathrm{R}$. Positions $\mathrm{P}_{-6}, \mathrm{P}_{-5}, \mathrm{P}_{-4}, \mathrm{P}_{1}, \mathrm{P}_{2}, \mathrm{P}_{4}$, and $\mathrm{P}_{5}$ of the PD1$\mathrm{Y}(-3) \mathrm{R}$ sequence were substituted with all other proteinogenous amino acids (given in one-letter code) and tested for binding to Lck SH3 (the manual assembly of spots in columns A and C was necessary due to an assignment aberration during membrane synthesis). For Lck SH3, every substituted position is shown, and for Src SH3, only position $\mathrm{P}_{-6}$ is shown. As a control, a column with PD1-Y $(-3) \mathrm{R}$ peptide spots is indicated at the right. PD1-Y(3)R peptides within the substitution membrane are encircled. (B) Plot of the spot intensities of position $\mathrm{P}_{-6}$ obtained after incubation of the membrane with GST-Lck SH3 (black bars) or GST-Src SH3 (gray bars) protein; the intensities for each peptide position was estimated as described in Materials and Methods. The arrangement of the peptides is in the same order as in panel A.

variants and documents that even the engineered PD1-Y(3)R peptide constitutes a suboptimal Lck SH3 ligand.

The Engineered PD1-Y(-3)R Ligand Belongs to a Group of Special Class I Ligands. With PD1, PD2, and PD4, three of our four phage-selected sequences have leucines at positions $\mathrm{P}_{-1}$ and $\mathrm{P}_{2}$ (Figure $1 \mathrm{~A}$ ), and therefore fulfill the requirements for a special type of class I ligand (Lig-I'), recently introduced by Serrano and co-workers (52). Briefly, Lig-I' ligands are characterized by their ability to bind to SH3 domains with a conserved Trp conformation normally supporting binding of class II ligands (SH3-II domains). The engineered high-affinity PD1-Y(-3)R peptide belongs to this special type of class I ligands, too. Only PD3 does not match exactly, as ligand position $\mathrm{P}_{2}$ is occupied by Phe instead of Leu. It is notable that the PD3 peptide did not bind to any of the assayed SH3 domains in the spot membrane assay (Figure 2A). From these results, we conclude that the conserved Trp in Lck SH3 might possibly prefer the SH3-II conformation. Supportively, Figure 4 summarizes the binding of Lck SH3 to a set of partially very similar ligand peptides, which were described as preferred ligands for the SH3 domains of Src, Fyn, PI3K, Abl, and Hck (42). In accordance with a probable preference for SH3-II conformation, Lck SH3 shows the tightest binding to three slightly different class II ligands. Binding of Lck to a class I' ligand was 


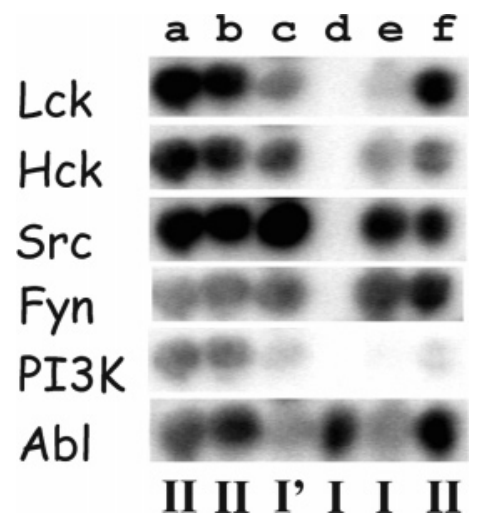

FIGURE 4: Binding of Lck and other SH3 domains to ligands of different classes. The experimental setup is as in Figure 2. The membrane was incubated with GST-SH3 fusion proteins as indicated at the left. Immobilized peptide sequences have been taken from previously reported studies from others, in which a preferred ligand for a certain SH3 domains had been selected (summarized in ref 42). Ligands a (RPPVPPRPGT), b (RPPVPPRPMT), c (RAARPLPPLPP), and d (PPPYPPPPP) are preferred ligands for Src, Fyn, PI3K, and Abl SH3 domains; ligands e (RRFRPLPPPP) and $\mathrm{f}$ (RPPVPPRPST) have been identified as preferred Hck SH3 ligands. The corresponding ligand class is indicated: I, Lig-I; I', Lig-I'; and II, Lig-II.

significant, although to a lower extent. Two different class I ligands yielded no or very weak binding to Lck SH3. Interestingly, the weak binding class I ligand contains one LP dipeptide required for class I' binding. The other Srctype PTK SH3 domains did not show such a clear preference for the appointed class II ligands, possibly indicating a more promiscuous orientation of their conserved Trp residues compared to that of Lck SH3. As expected, beside Abl SH3 itself, none of the other $\mathrm{SH} 3$ domains bound to the preferred Abl SH3 ligand.

Exploring the Lck SH3 Binding Regions of Native Lck SH3 Ligands. Only a small number of exact Lck SH3 binding sites within its native ligands are known. Therefore, we intended to identify as many of them as possible. Nearly all described Lck SH3 binding proteins play, often beside other functions, a role in the activation process of T-cells or are from viral sources interfering with T-cell activation, consistent with the cell-type specific distribution of Lck. All known Lck SH3 ligands were searched for regions that match simplified criteria for classical SH3 binding: "+xPxxP" for type I and "PxxPx+" for type II orientation. In cases where the original Lck SH3 binding experiments were carried out with peptides, which did not originate from human sources (e.g., mouse in the case of LckBP1 and FasL), we used the human counterparts in our study to refer to the physiological situation as close as possible. From each region that contains a potential SH3 binding motif, peptides comprising 15 amino acids were deduced. As in case of NS5A, more than one SH3-binding motif was found within a 15 -mer peptide. Thus, peptide variants with an alanine substitution of the respective anchor residues were analyzed, too. The respective synthetic peptides were immobilized on a cellulose membrane, and binding to the GST-Lck SH3 protein was assayed by an anti-GST ELISA (Figure 5).

In the case of ADAM15, CD2, CD28, HS1 (the human homologue of LckBP1), Nef, NS5A, SLP76, Sos, Tio, and TIP data are available regarding the position of the SH3 binding motif within the different proteins $(10,12,13,15-$

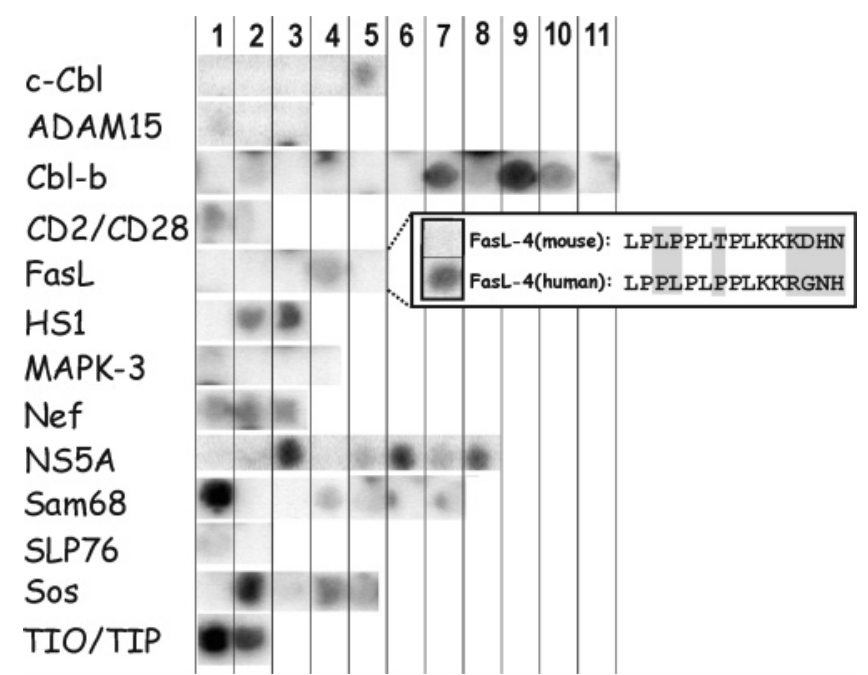

FIGURE 5: Analysis of binding of Lck SH3 to peptides from physiological ligands. Spot analyses of the binding affinities of peptides derived from known physiological Lck SH3 binding partners to Lck SH3. After incubation with GST-Lck SH3 protein, peptide-bound SH3 fusion protein was detected by a HRPconjugated anti-GST antibody and visualized by chemiluminescence. Peptides for immobilization were chosen as described in the text. Peptide names are given at the left. The respective peptide number is given at the top. All peptides are numbered according to their occurrence in the protein sequence and may therefore have a different numbering scheme as in the cited literature. Accession numbers of the used proteins as well as the position of the first amino acid of the deduced 15-mer peptides are given in parentheses. c-Cbl (P22681): c-Cbl-1 (490), c-Cbl-2 (527), c-Cbl-3 (536), c-Cbl-4 (541), c-Cbl-5 (816). ADAM15 (AAH14566): ADAM15-1 (742), ADAM15-2 (762), ADAM15-3 (797). Cbl-b (Q13191): Cblb-1 (420), Cbl-b-2 (500), Cbl-b-3 (543), Cbl-b-4 (557), Cbl-b-5 (581), Cbl-b-6 (668), Cbl-b-7 (773), Cbl-b-8 (818), Cbl-b-9 (863), Cbl-b-10 (898), Cbl-b-11 (970), CD2 (NP_001758, 297), CD28 (NP_031668, 201). FasL (AAO43991): FasL-1 (17), FasL-2 (39), FasL-3 (51), FasL-4 (62), FasL-5 (127). HS1 (P14317): HS1-1 (269), HS1-2 (319), HS1-3 (338). MAPK3 (P46734): MAPK3-1 (30), MAPK3-2 (281). MAPK4 (P45985): MAPK4-3 (23), MAPK4-4 (385). Nef: HIV-1 ${ }_{\mathrm{NL} 4-3}$ Nef (AAB60579, 68), HIV$1_{\mathrm{SF} 3} \mathrm{Nef}$ (AAC68849, 68), SIV $\mathrm{SIac}_{\text {m39 }}$ Nef (AAL78997, 100). NS5A (AAC15732, strain HC-J4): NS5A-1 (22), NS5A-2 (339), NS5A-3 (344), NS5A-4 (344, R356A substitution), NS5A-5 (344, K348A substitution), NS5A-6 (347), NS5A-7 (347, R356A substitution), NS5A-8 (347, K348A substitution). Sam68 (NP_006550): Sam68-1 (34), Sam68-2 (59), Sam68-3 (81), Sam68-4 (295), Sam68-5 (327), Sam68-6 (352), Sam68-7 (420). SLP76 (Q13094): SLP76-1 (182), SLP76-2 (400). Sos (NP_005624): Sos-1 (1020), Sos-2 (1147), Sos-3 (1173), Sos-4 (1207), Sos-5 (1284). TIO (NP_047977, 184): TIP (P22575, 171). Inset: $m$ (mouse), h (human), FasL-4 (mouse) (A53062, 62), FasL-4 (human) (AAO43991, 63). No binding of Lck SH3 to any peptide of the following proteins was detected in our study. hDlg (NP_004078): hDlg-1 (64), hDlg-2 (152), hDlg-3 (165), hDlg-4 (170). SH2-kinase linker Lck (P06239, 223). PI3K (NP_002640): PI3K-1 (303), PI3K-2 (365), PI3K-3 (555), PI3K-4 (779). PI4K (P42356): PI4K-1 (136), PI4K-2 (360), PI4K-3 (375), PI4K-4 (522). WASP (Q92558): WASP-1 (184), WASP-2 (270), WASP-3 (318), WASP-4 (347), WASP-5 (363), WASP-6 (380), WASP-7 (423), WASP-8 (461).

17, 43, 53-55). These proteins act as internal controls with which the degree of reliance of our experiment could be measured. The results of the spot assay agreed very well with the previously published data for ADAM15, CD2, HS1, SLP76, Nef, NS5A, Tio, and TIP, even though completely different methods had been used there to determine the regions relevant for Lck SH3 binding (e.g., peptide competition, immunoprecipitation, or deletion mutant analysis). For Sos, strong interaction with peptide 2 and a weaker one for 
peptides 3 and 5 are described (15). The study presented here yielded strong binding of Lck SH3 to Sos peptide 2 and, to some lesser extent, to Sos peptides 4 and 5. Whether this minor discrepancy is due to the fact that the peptides used in this study carried two additional residues is not clear. Interaction of Lck SH3 with the CD28-derived peptide was somehow weak, but detectable.

In contrast to the above-mentioned proteins, the positions of the relevant Lck SH3 binding regions within c-Cbl, Cblb, hDgl, FasL, MAPK3, MAPK4, PI3K, PI4K, Sam68, and WASP have not been identified so far $(9,11,18-20,56-$ 58 ). Because the assayed phosphatidylinositol kinase sequences (PI3K and PI4K) do not include regions matching any criteria for classical SH3 binding motifs ( + xxPxxP for type I and PxxPx + for type II), we probed all PI3K/PI4K regions containing a rudimentary "PxxP" motif. None of the respective PxxP-containing peptides resulted in a detectable interaction with the GST-Lck SH3 protein (data not shown). Also, no binding was found for all probed regions of $\mathrm{hDgl}$, the SH2 kinase linker region of Lck, and WASP (data not shown). Since short peptides are immobilized on the spot membrane, our experimental approach is restricted to Lck SH3 interaction partners comprising continuous, independent SH3 binding epitopes. Thus, one possible explanation for the negative results of PI3K/PI4K, hDlg, WASP, and the $\mathrm{SH} 2$ kinase linker region of Lck might be that in some cases isolated peptides might not reflect necessarily the situation of the whole protein context. The $\mathrm{SH} 2-\mathrm{CD}$ linker region of Src and Abl show, for example, a context-driven PPII conformation, which means that $\mathrm{SH} 3$ binding of these regions can only be observed in the presence of the scaffolding kinase domains $(59,60)$. In the case of MAPK, we could find a weak interaction of Lck SH3 with peptide MAPK3-1 (Figure 5), whose sequence (mskppapnptpprln) deviates from the classical SH3 binding motif. For the proteins c-Cbl, Cbl-b, Sam68, and human FasL, however, we were able to locate the putative Lck SH3 binding sites within these proteins (Figure 5).

Putative Lck SH3 Interaction Sites in c-Cbl and Cbl-b, Sam68, and FasL. The multifunctional proteins c-Cbl and Cbl-b are members of a family of proto-oncogenes involved in signal transduction. Both proteins are expressed in haematopoietic cells and share structural similarities characterized by an N-terminal SH2 domain, a RING-type zinc finger domain that interacts with E2 ubiquitin conjugating enzyme, and a $\mathrm{C}$-terminal proline-rich domain. $\mathrm{Cbl}$ family proteins negatively regulate $\mathrm{T}$-cell activation by promoting ligand-induced TCR down-modulation (61). A direct interaction of Lck SH3 was demonstrated with c-Cbl (9), which is a lipid raft-excluded protein and negatively regulates Lck localization in lipid rafts upon binding to it. Only peptide c-Cbl-5 (aa 816-830, gsqvperppkpfprr) within in the prolinerich region yielded a detectable interaction signal with Lck SH3 (Figure 5). Within Cbl-b, we identified three peptide sequences as putative binding sites for Lck SH3. Peptide Cbl-b-9 (aa 863-877, asgqvplpparrlpg) is the strongest putative Lck SH3 binding site in Cbl-b. Peptides Cbl-b-7 (aa 773-786, sdpvplpparppt) and Cbl-b-10 (aa 898-911, gsqaparppkprpr) yielded slightly weaker binding signals (Figure 5). We therefore suggest regions of residues 863877, 773-786, and 898-911 to be the putative Lck SH3 binding sites in Cbl-b.
Sam68 is a RNA-binding protein that has been found to be associated with c-Src and to be phosphorylated during mitosis $(62,63)$. Sam68 is composed of five proline-rich domains, a C-terminal tyrosine-rich region, and a $\mathrm{KH}$ domain. Therefore, Sam68 is able to recruit various polyproline-binding proteins. Sam68 seems to act as an adapter molecule participating in various signaling pathways, thereby forming interactions with different PTKs via their SH3 and SH2 domains dependent on cell type and activation state. In fibroblasts, Sam68 mainly interacts with c-Src (64); in the HTLV-1-infected Hayai cell line, Sam68 exhibits preferred binding to Fyn, and in uninfected Jurkat T-cells, binding of Sam68 to Fyn and Lck has been reported (20). In addition, interaction of Sam68 with the p86 subunit of PI3K was described previously (64). Spot analysis revealed a clearly preferred Lck SH3 binding site in Sam68-1 (aa 34-48, psrqpplphrsrgg). Peptides Sam68-4, -5, and -7 (aa 295-309, pppppvprgrgvgpp; aa 327-341, atvtrgvpppptvrg; aa 420434, rpslkapparpvkga) bound to Lck SH3 with significantly reduced affinity. This suggests residues $34-48$ of Sam68 to be the dominating Lck SH3 binding site in Sam68.

A couple of reports show a cooperation of Lck and human FasL activity (65-68). The Fas/FasL (Apo-1) system plays an important role in T-cell homeostasis (69). We checked possible binding of Lck SH3 to peptides comprising several regions within human FasL. A positive result was obtained for peptide FasL-4 comprising residues 62-76 (plpplplpplkkrgn) (Figure 5). Previously, it was shown that human Fyn, but not the Lck SH3 domain, directly binds to a synthetic peptide comprising residues 60-71 (qplplppltplk) of the mouse FasL protein (57). There are several differences in the amino acid sequences of mouse FasL and human FasL in the relevant region (Figure 5, inset). To control whether the assay used in our study is responsible for the somehow different result in binding of Lck SH3 to FasL, we decided to carry out an additional assay with peptides derived from mouse and human FasL in parallel (Figure 5, inlet). In agreement with the results of Hane and co-workers, Lck SH3 did not bind to the mouse FasL peptide in our study, either. But Lck SH3 reproducibly did bind to the human FasL peptide. Thus, according to our results, sorting and localization of human FasL could in principle be affected by $\mathrm{SH} 3$ domains other than Fyn SH3. More comprehensive experiments are necessary to confirm the interaction of FasL with Lck SH3 in living human cells. Confirmed binding between FasL and Lck in human but not in mouse would be a very interesting example of a species specific difference.

Natural Lck SH3 Ligands Bind Very Likely in the Type II Orientation. To identify common schemes among the Lck SH3 binding sites within its native ligands, all peptide sequences with binding spot intensities higher than 1000 arbitrary units, as estimated according to the approach described in Materials and Methods, are summarized in Figure 6. The peptide sequences agree to the consensus $N$-gxp(v/p)Pl(1/p)PPRprpr, where the residues depicted with bold uppercase letters are found in all peptides, residues depicted with uppercase letters are found frequently, and residues depicted with lowercase letters are moderately conserved at the corresponding position in each peptide ( $\mathrm{x}$ designates a residue without obvious preference for a specific amino acid). The core of the consensus is very similar to the $\Psi \mathrm{Pp} \Psi \mathrm{Pp}+$ pattern of typical class II ligands (24). Thus, 
$\mathbf{P}_{7} \mathbf{P}_{66} \mathbf{P}_{55} \mathbf{P}_{4} \mathbf{P}_{3} \mathbf{P}_{52} \mathbf{P}_{51} \mathbf{P}_{0} \mathbf{P}_{1} \mathbf{P}_{2} \mathbf{P}_{3} \mathbf{P}_{4} \mathbf{P}_{5} \mathbf{P}_{6}$

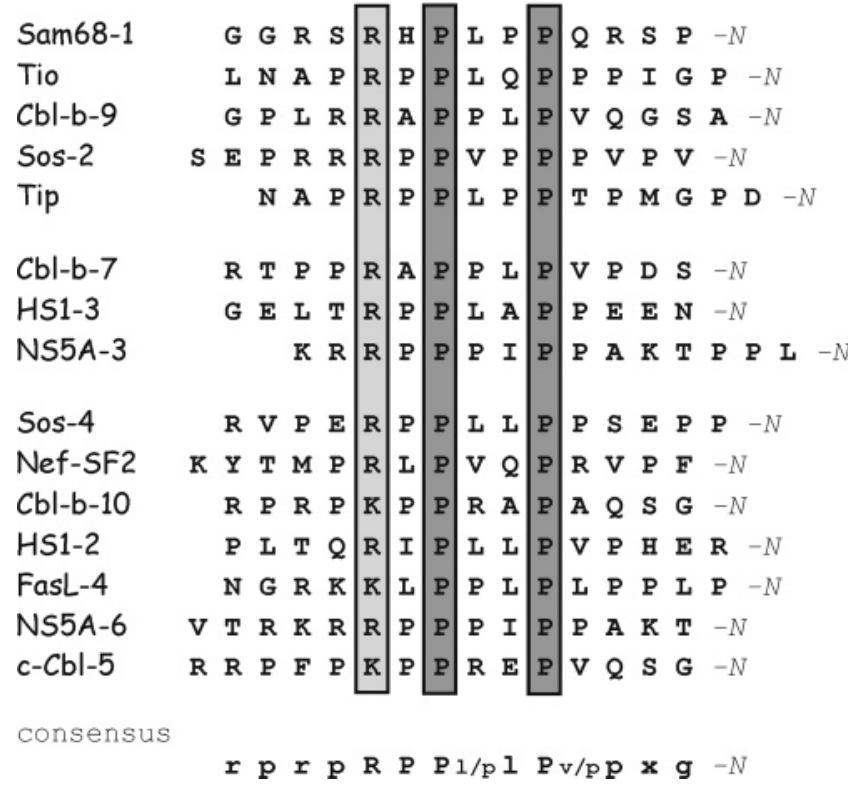

FIGURE 6: Multiple-sequence alignment of physiological Lck SH3 ligands. Alignment and ranking of the Lck SH3 binding peptides from the analyzed physiological binding partners. The ranking of the peptides is based on the spot intensity values from Figure 5, which were obtained as described in Materials and Methods. Binding strength was classified semiquantitatively according to the gained intensity values (arbitrary units). Peptides with values above 2500,1500 , and 1000 can be found in the top, middle, and bottom parts of the alignment, respectively. Please note that as in Figure 1 , the designations of the peptide sequence positions are according to Lim and co-workers (72), resulting in a $\mathrm{C}$ - to $\mathrm{N}$-terminal direction from left to right for all class II ligand peptides.

very strikingly and without exception, all peptides from natural Lck SH3 ligands exhibit features for binding in the type II orientation.

Overall, positions $\mathrm{P}_{-6}, \mathrm{P}_{-4}, \mathrm{P}_{3}$, and $\mathrm{P}_{4}$ tend to be occupied by prolines. It is notable that with only a few exceptions $\left(\mathrm{P}_{4}\right.$ in Nef_SF2 and Sos-2, and $\mathrm{P}_{5}$ in Tio), no hydrophobic amino acids occur at ligand positions $\mathrm{P}_{-4}, \mathrm{P}_{4}$, and $\mathrm{P}_{5}$. Aromatic amino acids do hardly occur, and cysteines do not at all appear at any position.

A positive net charge in the region comprising ligand positions $\mathrm{P}_{-7}-\mathrm{P}_{-4}$ seems to be favorable, as deduced from overall 16 positively and three negatively charged amino acids in that region among all peptides shown in Figure 6. Thus, peptide binding seems to be dependent on the presence of one or more auxiliary arginine residues located in the proximity of the $\mathrm{P}_{-3}$ "anchor residue". Contrary to the phage display-derived peptides, outside the core motif no dominant amino acid could be found at any position.

\section{DISCUSSION}

From our results, it is obvious that all peptides derived from native Lck SH3 binding proteins that were assayed for Lck SH3 binding with positive results belong to class II binders (Lig-II). The peptides obtained from the phage display screening approach, however, are ligands of Lck SH3 following the type I orientation. As already mentioned, they all belong to the special type of class I' peptides (Lig-I'), introduced and described in detail by Serrano and co-workers (52). In summary, they found that the side chain of a conserved Trp in the SH3 binding pocket can adopt two different orientations, classifying the respective $\mathrm{SH} 3$ domain structure, free or in complex, to be SH3-I and SH3-II. The orientation of the conserved Trp depends on the nature of a second residue located at a key position (residue 132 in Fyn, homologue to residue 110 in Lck) near the binding pocket. SH3 domains with $\beta$-branched or long aliphatic residues at this key position force the conserved Trp to adopt the SH3II orientation, whereas $\mathrm{SH} 3$ domains with aromatic residues in this key position are assumed to be promiscuous (52). The general rule concluded from their study is that Lig-I peptides bind to SH3-I domains and Lig-II peptides bind to SH3-II. Exceptions are Lig-I' peptides with Leu at position $\mathrm{P}_{-1}$ and Leu or Ala at position $\mathrm{P}_{2}$. According to their experiments, these two amino acids allow dihedral angle combinations that are not allowed for Pro residues mostly present in Lig-I ligands at the respective positions. Consequently, Lig-I' peptide backbones deviate from an ideal PPII helix and follow the trajectory of a Lig-II peptide, instead of Lig-I. Therefore, Lig-I' peptides bind to SH3-II domains, while maintaining the type I binding orientation.

Because a Phe is in the key position of Lck, a promiscuous binding behavior of Lck SH3 has been predicted (52). Thus, a mixture of Lig-I, Lig-I', and Lig-II peptides was expected to be the result of the phage display screening search for artificial Lck SH3 ligands. The exclusive observation of Lig$I^{\prime}$ peptides from the in vitro selection and the exclusive identification of Lig-II peptide sequences in Lck SH3's physiological binding partners suggest that in addition to the key residue other factors which govern the orientation of the conserved Trp residue exist. This is consistent with the three available structures of the ligand-free Lck SH3 domain [PDB entries 1H92, 1KIK, and 1LCK $(43,44,70)]$, which all are SH3-II, although the key residue is a Phe.

One of the most striking questions arising from this study is why the in vitro-selected peptides are Lig-I' and the peptides derived from the native ligands of Lck SH3 are LigII. To elucidate whether both ligand types show differences in their binding affinities, we determined the $K_{\mathrm{D}}$ values for the interactions of Lck SH3 with the artificial peptides PD1 and PD1-Y $(-3)$ R and with peptides Sam68-1, Sos-2, and NS5A-6. Dissociation constants between 20 and $170 \mu \mathrm{M}$ were obtained (Table 1), and the values of Lig-I' and Lig-II peptides are similar. Obviously, the $K_{\mathrm{D}}$ value alone is not the crucial parameter that can explain the observed class I and class II restrictions for in vitro-selected peptides and those obtained from physiological ligands, respectively. In this context, it is very interesting that the vast majority of SH3-Lig-I' three-dimensional complex structures determined so far by nuclear magnetic resonance spectroscopy and by X-ray crystallography contain Lig-I' peptides that originate from in vitro selection studies (PDB entries 1IO6, $1 \mathrm{NLO}, 1 \mathrm{NLP}, 1 \mathrm{AWF}, 1 \mathrm{RLP}$, and 1RLQ). The only exceptions are two structures of Fyn SH3 with a peptide comprising residues $91-104$ of p85 PI3K (PDB entries $1 \mathrm{AON}$ and 1AZG) with an Ala residue instead of Leu at ligand position $\mathrm{P}_{2}$. Also, high-affinity $\mathrm{SH} 3$ binding peptides obtained from phage display studies against other Src-type SH3 domains $(30,31)$, tend to be Lig-I'. The reason for this is not clear. These findings, together with our study, strongly suggest that in vitro-derived SH3 ligands be examined with caution when they are being compared with native ligands. A thermody- 
namic dissection of the binding energetics of proline-rich peptides with Abl SH3 showed striking and somewhat unexpected effects of slight modifications in peptide sequence on the enthalpic and entropic contributions of the respective binding interactions (71), confirming the complexity of SH3-ligand interactions.

It is obvious that physicochemical parameters for a complex formation under in vitro screening conditions with maximum diffusion rates of all molecules involved and in the absence of competing SH3 domains are completely different from the situation in a living cell, with drastically decreased diffusion rates of all molecules involved and in the presence of proteins that compete for a given ligand. This may explain the observed Lig-I' preference of Lck SH3 during a phage display selection approach. Further investigations are required to obtain comprehensive insight into the biophysical properties that biological complexes need to exert to be functional in living cells.

\section{ACKNOWLEDGMENT}

We thank Thomas Ast (JPT Peptide Technologies GmbH) for help with the peptide membrane handling.

\section{REFERENCES}

1. Sefton, B. M. (1991) The lck tyrosine protein kinase, Oncogene 6, 683-6.

2. Straus, D. B., and Weiss, A. (1992) Genetic evidence for the involvement of the lck tyrosine kinase in signal transduction through the $\mathrm{T}$ cell antigen receptor, Cell 70, 585-93.

3. Anderson, S. J., Levin, S. D., and Perlmutter, R. M. (1994) Involvement of the protein tyrosine kinase p56lck in $\mathrm{T}$ cell signaling and thymocyte development, Adv. Immunol. 56, 15178.

4. Resh, M. D. (1994) Myristylation and palmitylation of Src family members: The fats of the matter, Cell 11, 411-3.

5. Veillette, A., Bookman, M. A., Horak, E. M., and Bolen, J. B. (1988) The CD4 and CD8 T cell surface antigens are associated with the internal membrane tyrosine-protein kinase p56lck, Cell $55,301-8$.

6. Shaw, A. S., Chalupny, J., Whitney, J. A., Hammond, C., Amrein, K. E., Kavathas, P., Sefton, B. M., and Rose, J. K. (1990) Short related sequences in the cytoplasmic domains of CD4 and CD8 mediate binding to the amino-terminal domain of the p56lck tyrosine protein kinase, Mol. Cell. Biol. 10, 1853-62.

7. Isakov, N. (1998) Role of immunoreceptor tyrosine-based activation motif in signal transduction from antigen and $\mathrm{Fc}$ receptors, Adv. Immunol. 69, 183-247.

8. Reedquist, K. A., Fukazawa, T., Druker, B., Panchamoorthy, G., Shoelson, S. E., and Band, H. (1994) Rapid T-cell receptormediated tyrosine phosphorylation of p120, an Fyn/Lck Src homology 3 domain-binding protein, Proc. Natl. Acad. Sci. U.S.A. 91, 4135-9.

9. Hawash, I. Y., Kesavan, K. P., Magee, A. I., Geahlen, R. L., and Harrison, M. L. (2002) The Lck SH3 domain negatively regulates localization to lipid rafts through an interaction with c-Cbl, J. Biol. Chem. 277, 5683-91.

10. Holdorf, A. D., Green, J. M., Levin, S. D., Denny, M. F., Straus, D. B., Link, V., Changelian, P. S., Allen, P. M., and Shaw, A. S. (1999) Proline residues in CD28 and the Src homology (SH)3 domain of Lck are required for T cell costimulation, J. Exp. Med. 190, 375-84.

11. Prasad, K. V., Kapeller, R., Janssen, O., Repke, H., Duke-Cohan, J. S., Cantley, L. C., and Rudd, C. E. (1993) Phosphatidylinositol (PI) 3-kinase and PI 4-kinase binding to the CD4-p56lck complex: The p56lck SH3 domain binds to PI 3-kinase but not PI 4-kinase, Mol. Cell. Biol. 13, 7708-17.

12. Takemoto, Y., Furuta, M., Li, X. K., Strong-Sparks, W. J., and Hashimoto, Y. (1995) LckBP1, a proline-rich protein expressed in haematopoietic lineage cells, directly associates with the $\mathrm{SH} 3$ domain of protein tyrosine kinase p56lck, EMBO J. 14, 340314.
13. Sanzenbacher, R., Kabelitz, D., and Janssen, O. (1999) SLP-76 binding to p56lck: A role for SLP-76 in CD4-induced desensitization of the TCR/CD3 signaling complex, J. Immunol. 163, 314352.

14. Bell, G. M., Fargnoli, J., Bolen, J. B., Kish, L., and Imboden, J. B. (1996) The SH3 domain of p56lck binds to proline-rich sequences in the cytoplasmic domain of CD2, J. Exp. Med. 183, 169-78.

15. Park, C., Choi, Y., and Yun, Y. (1998) Son of sevenless binds to the SH3 domain of src-type tyrosine kinase, Mol. Cells 8, 51823.

16. Poghosyan, Z., Robbins, S. M., Houslay, M. D., Webster, A. Murphy, G., and Edwards, D. R. (2002) Phosphorylationdependent interactions between ADAM15 cytoplasmic domain and Src family protein-tyrosine kinases, J. Biol. Chem. 277, 49995007.

17. Macdonald, A., Crowder, K., Street, A., McCormick, C., and Harris, M. (2004) The hepatitis C virus NS5A protein binds to members of the Src family of tyrosine kinases and regulates kinase activity, J. Gen. Virol. 85, 721-9.

18. August, A., and Dupont, B. (1996) Association between mitogenactivated protein kinase and the $\zeta$ chain of the T cell receptor (TcR) with the SH2,3 domain of p56lck. Differential regulation by TcR cross-linking, J. Biol. Chem. 271, 10054-9.

19. Hanada, T., Lin, L., Chandy, K. G., Oh, S. S., and Chishti, A. H. (1997) Human homologue of the Drosophila discs large tumor suppressor binds to p56lck tyrosine kinase and Shaker type Kv1.3 potassium channel in T lymphocytes, J. Biol. Chem. 272, 26899904.

20. Fusaki, N., Iwamatsu, A., Iwashima, M., and Ji, F. (1997) Interaction between Sam68 and Src family tyrosine kinases, Fyn and Lck, in T cell receptor signaling, J. Biol. Chem. 272, 62149.

21. Larson, S. M., and Davidson, A. R. (2000) The identification of conserved interactions within SH3 domain by alignment of sequences and structures, Protein Sci. 9, 2170-80.

22. Kuriyan, J., and Cowburn, D. (1997) Modular peptide recognition domains in eukaryotic signaling, Аnпи. Rev. Biophys. Biomol. Struct. 26, 259-88.

23. Feng, S., Kasahara, C., Rickles, R. J., and Schreiber, S. L. (1995) Specific interactions outside the proline-rich core of two classes of Src homology 3 ligands, Proc. Natl. Acad. Sci. U.S.A. 92, 12408-15.

24. Feng, S., Chen, J. K., Yu, H., Simon, J. A., and Schreiber, S. L. (1994) Two binding orientations for peptides to the Src SH3 domain: Development of a general model for SH3-ligand interactions, Science 266, 1241-7.

25. Cesareni, G., Panni, S., Nardelli, G., and Castagnoli, L. (2002) Can we infer peptide recognition specificity mediated by $\mathrm{SH} 3$ domains? FEBS Lett. 513, 38-44.

26. Sparks, A. B., Quilliam, L. A., Thorn, J. M., Der, C. J., and Kay, B. K. (1994) Identification and characterisation of Src SH3 ligands from phage-displayed random peptide libraries, J. Biol. Chem. $269,23853-6$

27. Sparks, A. B., Adey, N. B., Quilliam, L. A., Thorn, J. M., and Kay, B. K. (1995) Screening phage-displayed random peptide libraries for SH3 ligands, Methods Enzymol. 255, 498-509.

28. Cheadle, C., Ivashchenko, Y., South, V., Searfoss, G. H., French, S., Howk, R., Ricca, G. A., and Jaye, M. (1994) Identification of a Src SH3 domain binding motif by screening a random phage display library, J. Biol. Chem. 269, 24034-9.

29. Rickles, R. J., Botfield, M. C., Zhou, X. M., Henry, P. A., Brugge, J. S., and Zoller, M. J. (1995) Phage display selection of ligand residues important for Src homology 3 domain binding specificity, Proc. Natl. Acad. Sci. U.S.A. 92, 10909-13.

30. Sparks, A. B., Rider, J. E., Hoffman, N. G., Fowlkes, D. M., Quillam, L. A., and Kay, B. K. (1996) Distinct ligand preferences of Src homology 3 domains from Src, Yes, Abl, Cortactin, p53bp2, PLCgamma, Crk, and Grb, Proc. Natl. Acad. Sci. U.S.A. 93, 1540-4.

31. Rickles, R. J., Botfield, M. C., Weng, Z., Taylor, J. A., Green, O. M., Brugge, J. S., and Zoller, M. J. (1994) Identification of Src, Fyn, Lyn, PI3K and Abl SH3 domain ligands using phage display libraries, EMBO J. 13, 5598-604.

32. Bunnell, S. C., Henry, P. A., Kolluri, R., Kirchhausen, T., Rickles, R. J., and Berg, L. J. (1996) Identification of Itk/Tsk Src homology 3 domain ligands, J. Biol. Chem. 271, 25646-56. 
33. Kurakin, A., Hoffman, N. G., and Kay, B. K. (1998) Molecular recognition properties of the C-terminal Sh3 domain of the $\mathrm{Cbl}$ associated protein, Cap, J. Pept. Res. 52, 331-7.

34. Mongiovi, A. M., Romano, P. R., Panni, S., Mendoza, M., Wong, W. T., Musacchio, A., Cesareni, G., and Di Fiore, P. P. (1999) A novel peptide-SH3 interaction, EMBO J. 18, 5300-9.

35. Cestra, G., Castagnoli, L., Dente, L., Minenkova, O., Petrelli, A., Migone, N., Hoffmuller, U., Schneider-Mergener, J., and Cesareni, G. (1999) The SH3 domains of endophilin and amphiphysin bind to the proline-rich region of synaptojanin 1 at distinct sites that display an unconventional binding specificity, J. Biol. Chem. 274, $32001-7$.

36. Fazi, B., Cope, M. J., Douangamath, A., Ferracuti, S., Schirwitz, K., Zucconi, A., Drubin, D. G., Wilmanns, M., Cesareni, G., and Castagnoli, L. (2002) Unusual binding properties of the SH3 domain of the yeast actin-binding protein Abp1: Structural and functional analysis, J. Biol. Chem. 277, 5290-8.

37. Kay, B. K., Williamson, M. P., and Sudol, M. (2000) The importance of being proline: The interaction of proline-rich motifs in signaling proteins with their cognate domains, FASEB J. 14, 231-41.

38. Mayer, B. J. (2001) SH3 domains: Complexity in moderation, $J$. Cell Sci. 114, 1253-63.

39. Musacchio, A. (2002) How SH3 domains recognize proline, $A d v$. Protein Chem. 61, 211-68.

40. Agrawal, V., and Kishan, K. V. (2002) Promiscuous binding nature of SH3 domains to their target proteins, Protein Pept. Lett. 9 , 185-93.

41. Tong, A. H., Drees, B., Nardelli, G., Bader, G. D., Brannetti, B., Castagnoli, L., Evangelista, M., Ferracuti, S., Nelson, B., Paoluzi, S., Quondam, M., Zucconi, A., Hogue, C. W., Fields, S., Boone, C., and Cesareni, G. (2002) A combined experimental and computational strategy to define protein interaction networks for peptide recognition modules, Science 295, 321-4.

42. Brannetti, B., Via, A., Cestra, G., Cesareni, G., and Citterich, M H. (2000) SH3-SPOT: An algorithm to predict preferred ligands to different members of the SH3 gene family, J. Mol. Biol. 298, 313-28.

43. Schweimer, K., Hoffmann, S., Bauer, F., Friedrich, U., Kardinal, C., Feller, S. M., Biesinger, B., and Sticht, H. (2002) Structural investigation of the binding of a herpesviral protein to the $\mathrm{SH} 3$ domain of tyrosine kinase Lck, Biochemistry 41, 5120-30.

44. Briese, L., and Willbold, D. (2003) Structure determination of human Lck unique and SH3 domains by nuclear magnetic resonance spectroscopy, BMC Struct. Biol. 3, 3.

45. Gill, S. C., and von Hippel, P. H. (1989) Calculation of protein extinction coefficients from amino acid sequence data, Anal. Biochem. 182, 319-26.

46. Nettelbeck, D. M., Miller, D. W., Jerome, V., Zuzarte, M., Watkins, S. J., Hawkins, R. E., Muller, R., and Kontermann, R. E. (2001) Targeting of adenovirus to endothelial cells by a bispecific single-chain diabody directed against the adenovirus fiber knob domain and human endoglin (CD105), Mol. Ther. 3, 882-91.

47. Ghose, R., Shekhtman, A., Goger, M. J., Ji, H., and Cowburn, D. (2001) A novel, specific interaction involving the Csk SH3 domain and its natural ligand, Nat. Struct. Biol. 8, 998-1004.

48. Cicchetti, P., Mayer, B. J., Thiel, G., and Baltimore, D. (1992) Identification of a protein that binds to the $\mathrm{SH} 3$ region of $\mathrm{Abl}$ and is similar to Bcr and GAP-rho, Science 257, 803-6.

49. Musacchio, A., Saraste, M., and Wilmanns, M. (1994) Highresolution crystal structures of tyrosine kinase SH3 domains complexed with proline-rich peptides, Nat. Struct. Biol. 1, 54651.

50. Alexandropoulos, K., Cheng, G., and Baltimore, D. (1995) Prolinerich sequences that bind to Src homology 3 domains with individual specificities, Proc. Natl. Acad. Sci. U.S.A. 92, 31104.

51. Peters, E. A., Schatz, P. J., Johnson, S. S., and Dower, W. J. (1994) Membrane insertion defects caused by positive charges in the early mature region of protein pIII of filamentous phage $\mathrm{fd}$ can be corrected by prlA suppressors, J. Bacteriol. 176, 4296-305.

52. Fernandez-Ballester, G., Blanes-Mira, C., and Serrano, L. (2004) The tryptophan switch: Changing ligand-binding specificity from type I to type II in SH3 domains, J. Mol. Biol. 335, 619-29.
53. Greenway, A., Azad, A., Mills, J., and McPhee, D. (1996) Human immunodeficiency virus type 1 Nef binds directly to Lck and mitogen-activated protein kinase, inhibiting kinase activity, $J$. Virol. 70, 6701-8.

54. Albrecht, J. C., Friedrich, U., Kardinal, C., Koehn, J., Fleckenstein, B., Feller, S. M., and Biesinger, B. (1999) Herpesvirus ateles gene product Tio interacts with nonreceptor protein tyrosine kinases, J. Virol. 73, 4631-9.

55. Biesinger, B., Tsygankov, A. Y., Fickenscher, H., Emmrich, F., Fleckenstein, B., Bolen, J. B., and Broker, B. M. (1995) The product of the Herpesvirus saimiri open reading frame 1 (tip) interacts with $\mathrm{T}$ cell-specific kinase p56lck in transformed cells, J. Biol. Chem. 270, 4729-34.

56. Keane, M. M., Rivero-Lezcano, O. M., Mitchell, J. A., Robbins, K. C., and Lipkowitz, S. (1995) Cloning and characterization of cbl-b: A SH3 binding protein with homology to the c-cbl protooncogene, Oncogene 10, 2367-77.

57. Hane, M., Lowin, B., Peitsch, M., Becker, K., and Tschopp, J. (1995) Interaction of peptides derived from the Fas ligand with the Fyn-SH3 domain, FEBS Lett. 373, 265-8.

58. Zhu, Q., Watanabe, C., Liu, T., Hollenbaugh, D., Blaese, R. M., Kanner, S. B., Aruffo, A., and Ochs, H. D. (1997) Wiskott-Aldrich syndrome/X-linked thrombocytopenia: WASP gene mutations, protein expression, and phenotype, Blood 90, 2680-9.

59. Xu, W., Harrison, S. C., and Eck, M. J. (1997) Three-dimensional structure of the tyrosine kinase c-Src, Nature 385, 595-602.

60. Barila, D., and Superti-Furga, G. (1998) An intramolecular SH3domain interaction regulates c-Abl activity, Nat. Genet. 18, 280-

61. Naramura, M., Jang, I. K., Kole, H., Huang, F., Haines, D., and $\mathrm{Gu}, \mathrm{H}$. (2002) c-Cbl and Cbl-b regulate T cell responsiveness by promoting ligand-induced TCR down-modulation, Nat. Immunol. 3, 1192-9.

62. Taylor, S. J., and Shalloway, D. (1994) An RNA-binding protein associated with $\mathrm{Src}$ through its $\mathrm{SH} 2$ and $\mathrm{SH} 3$ domains in mitosis, Nature 368, 867-71.

63. Fumagalli, S., Totty, N. F., Hsuan, J. J., and Courtneidge, S. A. (1994) A target for Src in mitosis, Nature 368, 871-4.

64. Taylor, S. J., Anafi, M., Pawson, T., and Shalloway, D. (1995) Functional interaction between c-Src and its mitotic target, Sam 68, J. Biol. Chem. 270, 10120-4.

65. Chung, C. D., Lewis, L. A., and Miceli, M. C. (1997) T cell antigen receptor-induced IL-2 production and apoptosis have different requirements for Lck activities, J. Immunol. 159, 1758-66.

66. Kessler, B., Hudrisier, D., Schroeter, M., Tschopp, J., Cerottini, J. C., and Luescher, I. F. (1998) Peptide modification or blocking of CD8, resulting in weak TCR signaling, can activate CTL for Fas- but not perforin-dependent cytotoxicity or cytokine production, J. Immunol. 161, 6939-46.

67. Yu, X. Z., Levin, S. D., Madrenas, J., and Anasetti, C. (2004) Lck is required for activation-induced $\mathrm{T}$ cell death after TCR ligation with partial agonists, J. Immunol. 172, 1437-43.

68. Gonzalez-Garcia, A., L, R. B., Leonardo, E., Merida, I., Martinez, A. C., and Carrera, A. C. (1997) Lck is necessary and sufficient for Fas-ligand expression and apoptotic cell death in mature cycling T cells, J. Immunol. 158, 4104-12.

69. Li-Weber, M., and Krammer, P. H. (2003) Function and regulation of the CD95 (APO-1/Fas) ligand in the immune system, Semin. Immunol. 15, 145-57.

70. Eck, M. J., Atwell, S. K., Shoelson, S. E., and Harrison, S. C. (1994) Structure of the regulatory domains of the Src-family tyrosine kinase Lck, Nature 368, 764-9.

71. Palencia, A., Cobos, E. S., Mateo, P. L., Martinez, J. C., and Luque, I. (2004) Thermodynamic dissection of the binding energetics of proline-rich peptides to the Abl-SH3 domain: Implications for rational ligand design, J. Mol. Biol. 336, 527-37.

72. Lim, W. A., Richards, F. M., and Fox, R. O. (1994) Structural determinants of peptide-binding orientation and of sequence specificity in SH3 domains, Nature 372, 375-9.

BI051403K 